\title{
39. STRUCTURE AT THE TOE OF THE SUBDUCTION COMPLEX: MIDDLE AMERICA TRENCH OFFSHORE GUATEMALA ${ }^{1}$
}

\author{
E. L. Ambos and D. M. Hussong, Hawaii Institute of Geophysics ${ }^{2}$
}

\begin{abstract}
During DSDP Leg 67, seismic refraction data were collected in the lower slope region of the Middle America Trench using ocean-bottom seismometers. Near the trench, the transition between the overlying (Caribbean) and underlying (Cocos) plates was found to be marked by an abrupt velocity increase. Landward of the trench, velocities in the upper plate increase, and as a consequence the plate/plate boundary is seismically less clearly defined. The landward velocity increase in the upper plate is gradual, and no evidence was found to suggest the existence of imbedded slabs of highvelocity ocean crust.
\end{abstract}

\section{INTRODUCTION}

The Middle America Trench offshore Guatemala (MAT-G) is of continuing tectonic and geologic interest, as evidenced by the mandate for additional DSDP drilling during Leg 84. Multichannel seismic data originally aided in defining the lower-slope subduction complex (nomenclature according to Dickinson and Seely, 1979) as the type accretionary prism (Seely et al., 1974). Drilling during Leg 67, and more recently Leg 84 , demonstrated the contrary. We now know that this forearc region is actively subsiding (von Huene and Aubouin, 1982). Instead of accretion, erosion and subduction of the overlying Caribbean Plate may be occurring.

In conjunction with DSDP Leg 67, the Hawaii Institute of Geophysics (HIG) conducted a seismic refraction experiment in the vicinity of the MAT-G. Previous multichannel seismic reflection data (Ladd et al., 1978, and Ladd et al., 1982) had indicated the existence of a prominent reflector marking the plate/plate interface (particularly noticeable on their GUA-2 and GUA-4 lines). In addition, seismic refraction data (Ibrahim et al., 1979) provided evidence for the presence of high-velocity sections within the subduction complex, which could be interpreted as accreted slices of ocean crust. Therefore, the purpose of our experiment was to determine the velocity structure at the toe of the subduction complex, including the transition with depth from overriding to subducting plate. A secondary aim was to find evidence supporting or denying the existence of slabs of high-velocity material (ocean crust) imbedded within the subduction complex.

\section{METHODS}

\section{Data Acquisition}

Four seismic refraction lines (Fig. 1) were shot by using Tovex explosives of 5 to $120 \mathrm{lbs}$. charge weight. The lines ranged from 60 to

\footnotetext{
${ }^{1}$ von Huene, R., Aubouin, J., et al., Init. Repts. DSDP, 84: Washington (U.S. Govt. Printing Office).

2 Address: (Ambos, present address) U.S. Geological Survey, 345 Middlefield Rd., MS977, Menlo Park, CA 94025; (Hussong) Hawaii Inst. of Geophysics, 2525 Correa Rd., Honolulu, HI 96822 .
}

$180 \mathrm{~km}$ in length, and the shot spacing was typically $1 \mathrm{~km}$ out to 30 $\mathrm{km}$ range, then $3 \mathrm{~km}$ to the end of the line. Two lines were shot parallel to the strike of the Middle America Trench. Line 2 was shot along the trend of a prominent terrace of the trench inner slope, and part of line 4 was shot upslope from and parallel to line 2 . The other side of the line 4 split-spread crossed very close to the trench axis. Lines 3 and 5 trended subperpendicular to the trench, crossing from the Cocos Plate to the trench inner slope of the Caribbean Plate.

Receivers used were five HIG OBSs (Ocean-Bottom Seismometers), which record vertical and horizontal geophone $(4.5-\mathrm{Hz}$ natural frequency), hydrophone, and internally generated time-code signals on analog tape cassettes (see Sutton et al., 1977, for a more complete description of the instrumentation). Three of the OBSs (N, D, and J) were deployed in a line on the terrace previously mentioned (Fig. 2). OBS $\mathrm{Z}$ was deployed on the trench floor, and OBS A was emplaced farther up the lower slope.

After retrieval of the OBSs, the original analog data were converted to digital format and stored on magnetic tape. Record section plots were made of all shotline-OBS combinations. Any discrepancies between the OBS internal time code and WWV (the U.S. Bureau of Standards broadcast time standard) because of drift of the internal clock were corrected at that time. Initial navigation was based on satellite navigation fixes taken every few hours, and radar fixes of the Glomar Challenger from the Kana Keoki. To check the shot and receiver positioning, the water-wave traveltimes for all shots were measured. These arrival times, which were picked to a precision of 0.02 , were then used to locate shots and receivers, by means of a least-squares inversion (Sinton, 1982). The final OBS and shot locations were determined to within $\pm 150 \mathrm{~m}$.

\section{Data Analysis and Interpretation}

Five shotline-OBS combinations were ultimately chosen for analysis: line 2, OBS D; line 4, OBSs J and D; line 3, OBS D; and line 5, OBS $\mathrm{Z}$. The criteria for choice were data quality and proximity of the OBS to the shotline. The vertical geophone channel was chosen in all cases, except for line 5 , OBS $\mathrm{Z}$, for which the data from the hydrophone channel were analyzed.

The lines shot parallel to structure, line 2 and the northwestern portion of line 4, were interpreted first. The bottom topography under these lines was relatively smooth; variation was on the order of $500 \mathrm{~m}$ or less. Any topographic corrections applied to these data would be small, so that timing changes made to the data would have less probability of producing error (see Purdy, 1982, for an analysis of errors induced by topographic corrections). In addition, we made the first-order assumption that lines parallel to structure should sample materials that are laterally homogenous. We have support for this assumption, as both gravity (Couch and Woodcock, 1981) and magnetics (Ladd, et al., 1982) data show anomaly trends parallel to trench strike. For these two reasons, we first used traveltime-inversion methods, which require lateral velocity homogeneity, to interpret line 2 and the northwestern side of line 4 split-spread. The southeastern side of line 4 was not interpreted in this manner, because the line crosses from the Caribbean Plate to 


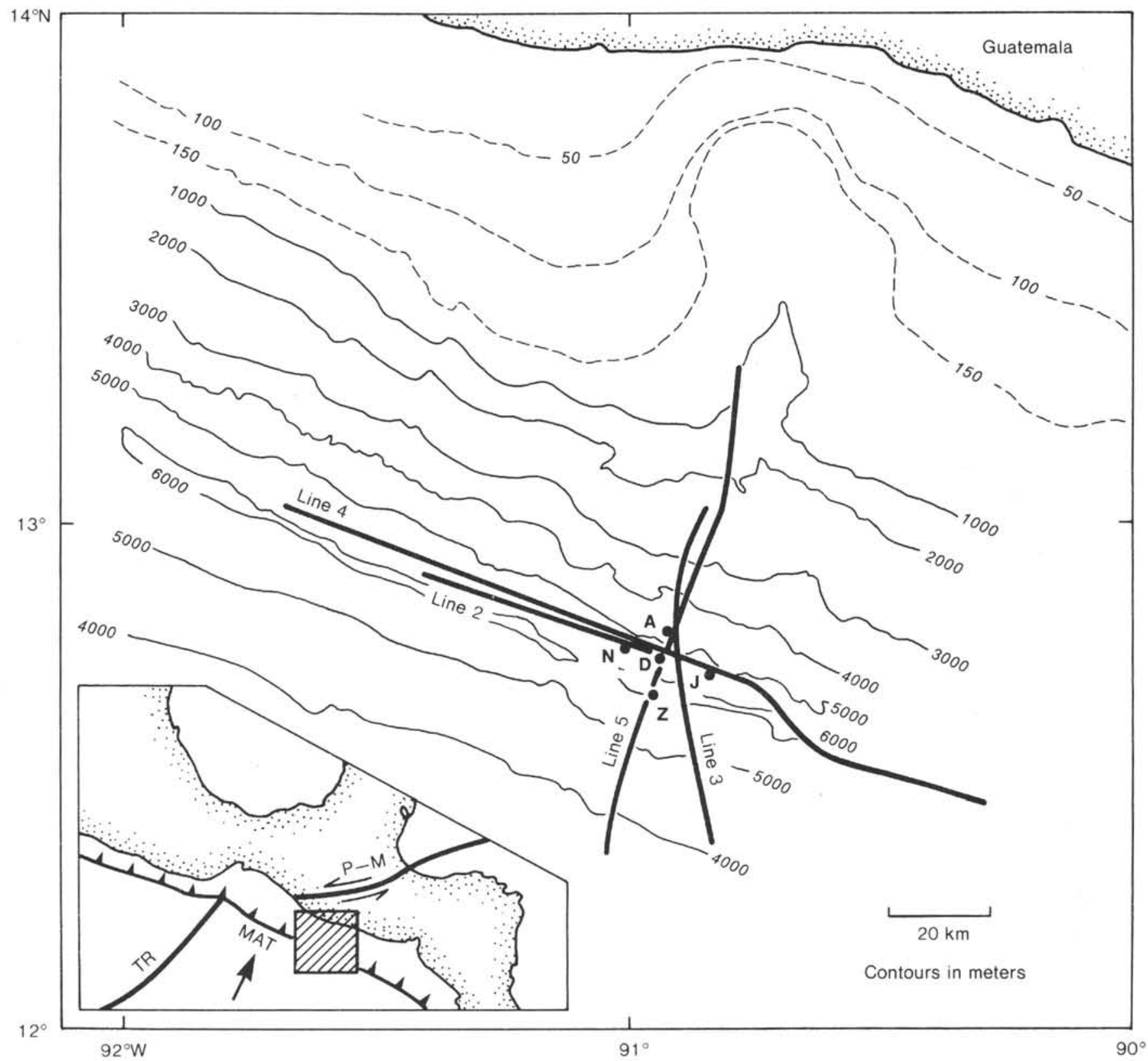

Figure 1. Location of the MAT-G seismic refraction experiment. Inset identifies the following tectonic features: MAT = Middle America Trench. P$\mathrm{M}=$ Polochic, Motagua, and associated left-lateral faults marking the North America/Caribbean Plate boundary in Guatemala. TR = Tehuantepec Ridge, a prominent offshore ridge separating the Mexican and Guatemalan portions of the Middle America Trench. The main diagram indicates the locations of seismic lines and OBSs A, D, J, N, and Z. The 6000 -m bathymetry contour roughly defines the trench-axis location.

the Cocos Plate, which would clearly violate the requirement of lateral homogeneity.

The inversion scheme employed is that developed by Dorman and Jacobson (1981). Following their method, traveltime data corrected to a seafloor datum are fit with a piecewise smooth function (a polynomial or spline) and tau and $p$ data points determined along the curve. These data are reparameterized as tau and zeta; zeta merely being the quantity $T+p x$. As a linear relationship exists between tau, zeta, and velocity gradient as a function of depth, one can solve for the latter by using standard linear programming schemes. The error bounds and resolution of this solution are also calculated. Ultimately, the velocity gradient is integrated, resulting in the desired velocity-versus-depth function. The advantage of the method is that it provides a statistically significant estimate of the solution. The disadvantage, common to most traveltime-inversion schemes, is that it utilizes only first-arrival times. Thus, second-arrival and amplitude information cannot be used to constrain the velocity-depth function. To take as full advantage as possible of our data set, we also used raytracing and synthetic construction in our analysis. The method we chose allowed lateral heterogeneity, so that we were able to use the cross-structure lines, 3,5 , and the southeast portion of line 4 . We used the raytrace method described by Sinton and Frazer (1982) and Sinton (1982), which is based on an algorithm developed by Gebrande (1976). Synthetic seismograms may be constructed by using the raytrace information, following the Extended WKBJ theory described by Frazer and Phinney (1980) and Sinton and Frazer (1982).

The general procedure, then, was first to obtain initial models for line 2 and the northwestern side of line 4 from first-arrival traveltime 


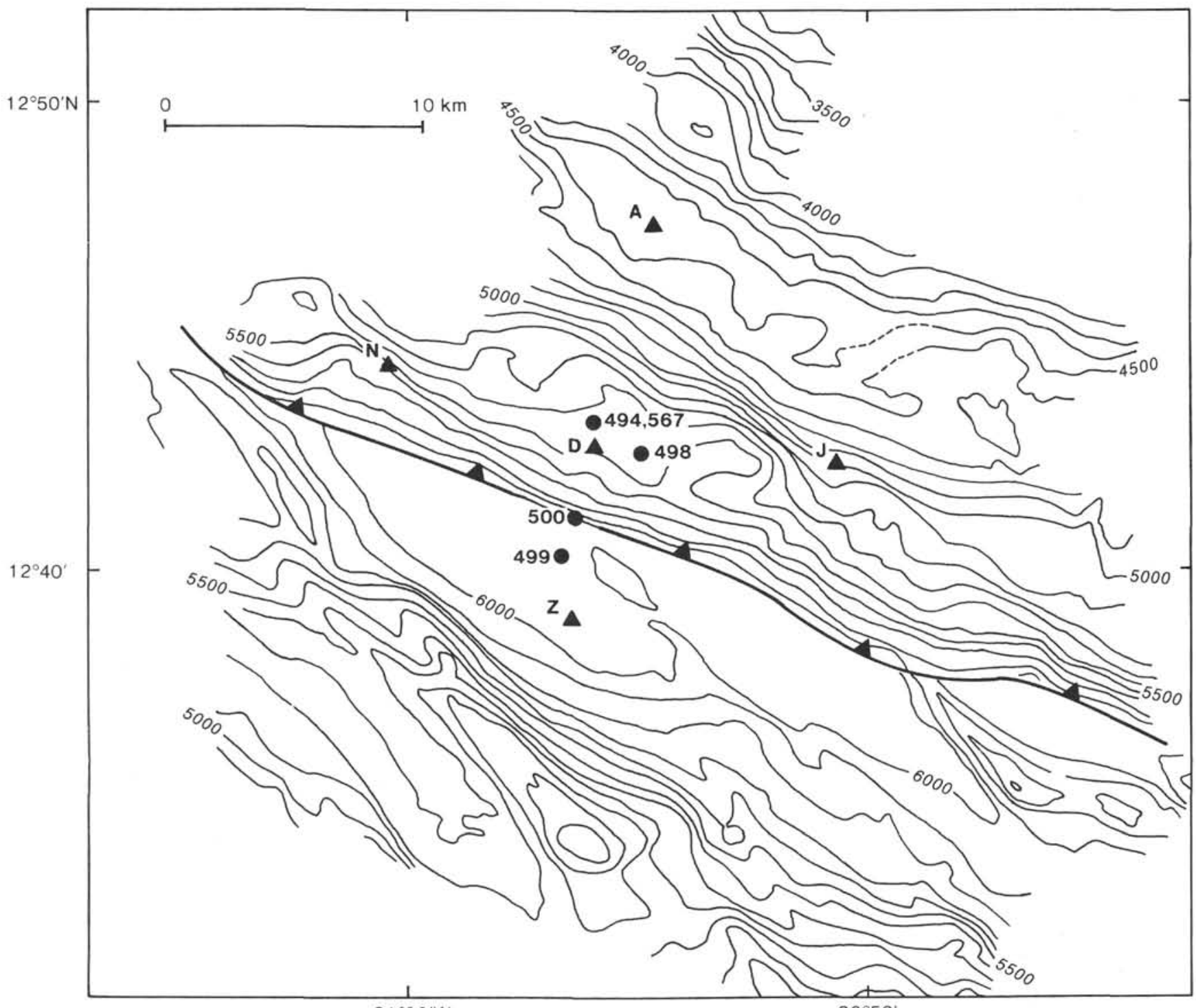

$91^{\circ} \mathrm{OO} \mathrm{W}$

$90^{\circ} 50^{\prime}$

Figure 2. Closeup of the OBS deployment sites and DSDP Legs 67 and 84 drill holes. Bathymetry (in meters) after Aubouin, Stephan, et al., (1982).

inversion, then to iterate on these models through raytracing. With these refined velocity functions as starting points, the cross-structure lines, 3 and 5 , and the southeastern portion of line 4 , were modeled. Raytracing was used, with the requirement of agreement at seismic-line crossover points.

The available multichannel seismic reflection and geologic data were considered throughout the data analysis. Construction of the models naturally required certain assumptions concerning the geologic and tectonic setting of the survey area. Such assumptions are necessary for the choice of a "best" model, and in a qualitative fashion improve the stability of the solution.

\section{RESULTS AND INTERPRETATION}

\section{Line 2}

The data for line 2 are displayed in record section format, without topographic corrections of any sort applied (Fig. 3). As described in the previous section, we chose to perform an inversion of the first-arrival traveltimes in order to obtain a starting model. For this purpose, shots were corrected to the seafloor, according to the procedure outlined by Spudich and Orcutt (1980). Traveltimes were then picked and assigned errors ranging from 20 (for very clear, impulsive arrivals) to $50 \mathrm{~m}$ (for emergent arrivals). Two second-order polynomials were fit to the traveltime curve, with residuals of fit on the order of $0.05-$ $0.10 \mathrm{~s}$. Tau and zeta points were parameterized from these functions, inverted, and a velocity-depth function was produced (Fig. 4B). The most prominent feature of the function is the rapid increase in velocity, between 1.5 and $3 \mathrm{~km}$ sub-bottom depth, from 3.5 to $5.3 \mathrm{~km} / \mathrm{s}$. This is shown more dramatically as a change in velocity gradient (Fig. 4C).

The solid line superimposed on the first-arrival portion of the seismogram (Fig. 4A) shows the traveltime curve produced by the velocity-depth function (Fig. 4B). This velocity structure evidently produces a good fit to the first arrival times but, as was originally suspected, fails to match the prominent second arrivals (dashed circled areas). Consequently, raytracing was undertaken to 
Line 2 - OBS D

A

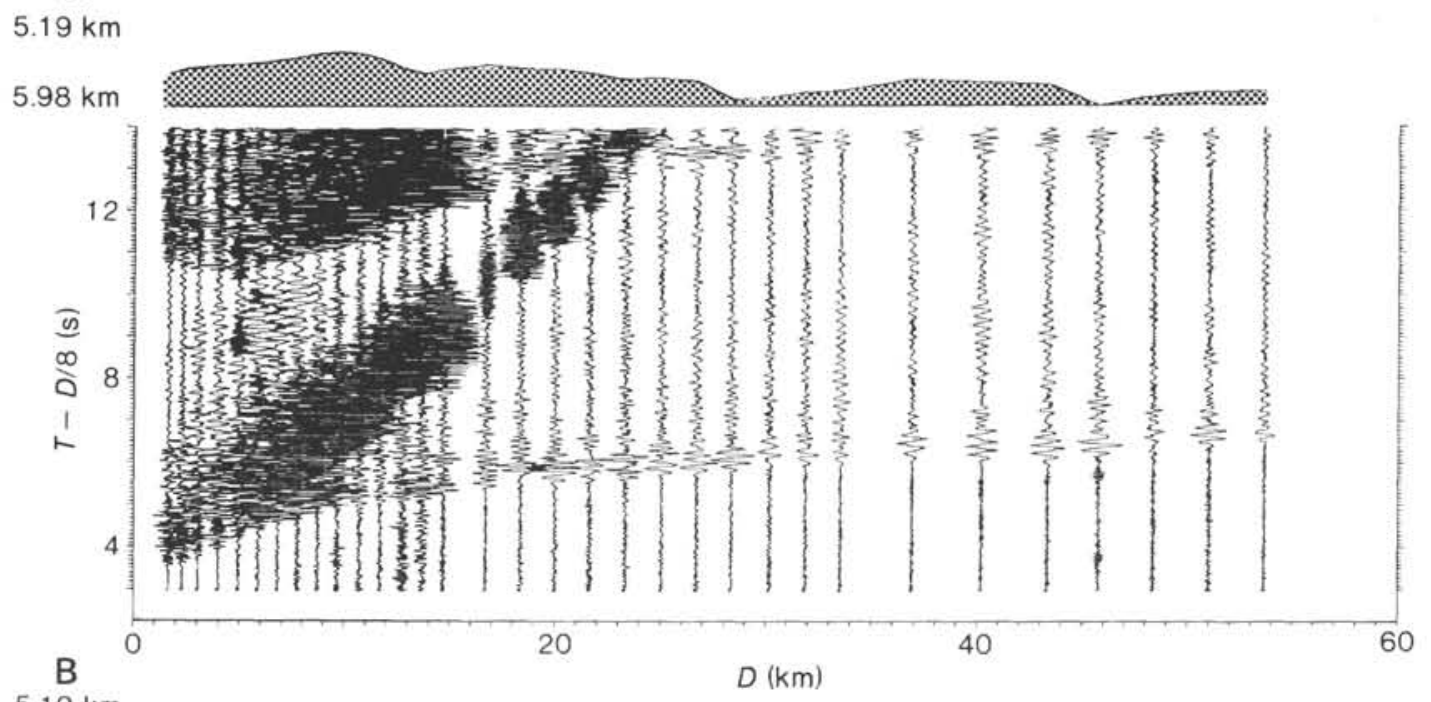

$5.19 \mathrm{~km}$

$5.50 \mathrm{~km}$

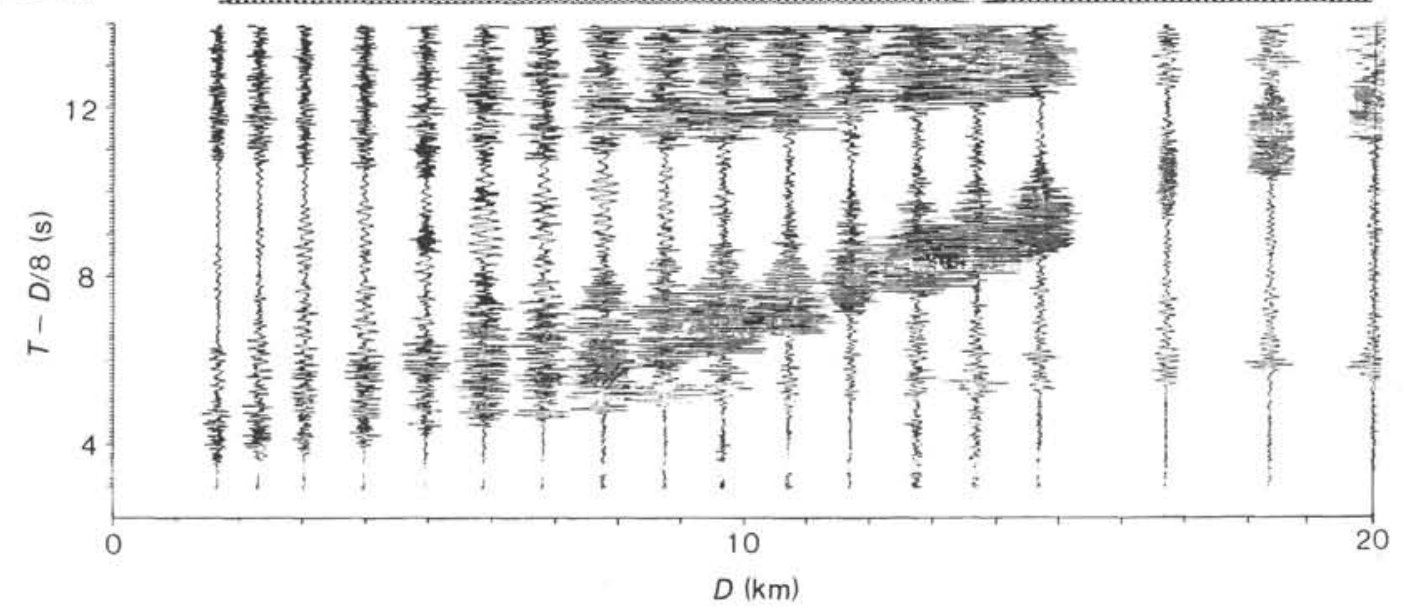

Figure 3. A. Record section for line 2, recorded by OBS D without any topographic corrections or interpretation. Unless indicated otherwise, for this and subsequent illustrations of data the following are true: (1) Data are filtered from 2$20 \mathrm{~Hz}$ with a 4-pole Butterworth filter. (2) A reducing velocity of $8.0 \mathrm{~km} / \mathrm{s}$ has been applied, so that the time axis is $T-D / 8$ (traveltime $[T]$ minus distance $[D] / 8.0$ ). (3) Bathymetric relief is displayed above the data; numbers in the upper left-hand corner are the shallowest and deepest bathymetric points under the shotline. (4) Original trace amplitudes have been adjusted for recorded gain differences and multiplied by (a) [shot range/reference range] ${ }^{1.2}$, to account for geometrical spreading loss, and (b) [reference shot weight/shot weight $]^{0.66}$, to balance varying shot sizes. The reference shot is that one closest to the receiver. B. Detail of record section shown in $3 \mathrm{~A} ; 0-20 \mathrm{~km}$ range.

produce a model fitting these prominent features of the data. The initial model included the bathymetry variation under the shot line, as picked from $3.5-\mathrm{kHz}$ PDR records. The subsurface structure was that derived from the traveltime inversion, assumed to be one-dimensional until subsequent evidence to the contrary was observed from the raytracing results.

Figure 5A shows the structure determined through raytracing, with representative rays drawn. Figure 5B shows the traveltime curves superimposed on the actual data, compared with synthetic data generated from this model. The synthetic appears to match most of the large-scale features of the observed data. Differences exist, of course, between real and synthetic data, particularly in the am- plitudes and frequencies of arrivals in the $30-40 \mathrm{~km}$ range. We attribute these differences to the fact that multiple arrivals, which have been shown by Kempner and Gettrust (1982) to be significant, are not calculated in our method. For example, Kempner and Gettrust showed that the PmP (reflection from the crust/mantle boundary) and PmPPmp (multiple reflection) in the $30-40 \mathrm{~km}$ range may interfere constructively or destructively, resulting in differing waveforms, frequencies, and amplitudes from those that would be observed if only the PmP were modeled.

Despite these inadequacies, it is evident that this model represents an improvement over that derived through traveltime inversion, because it fits most of the salient 

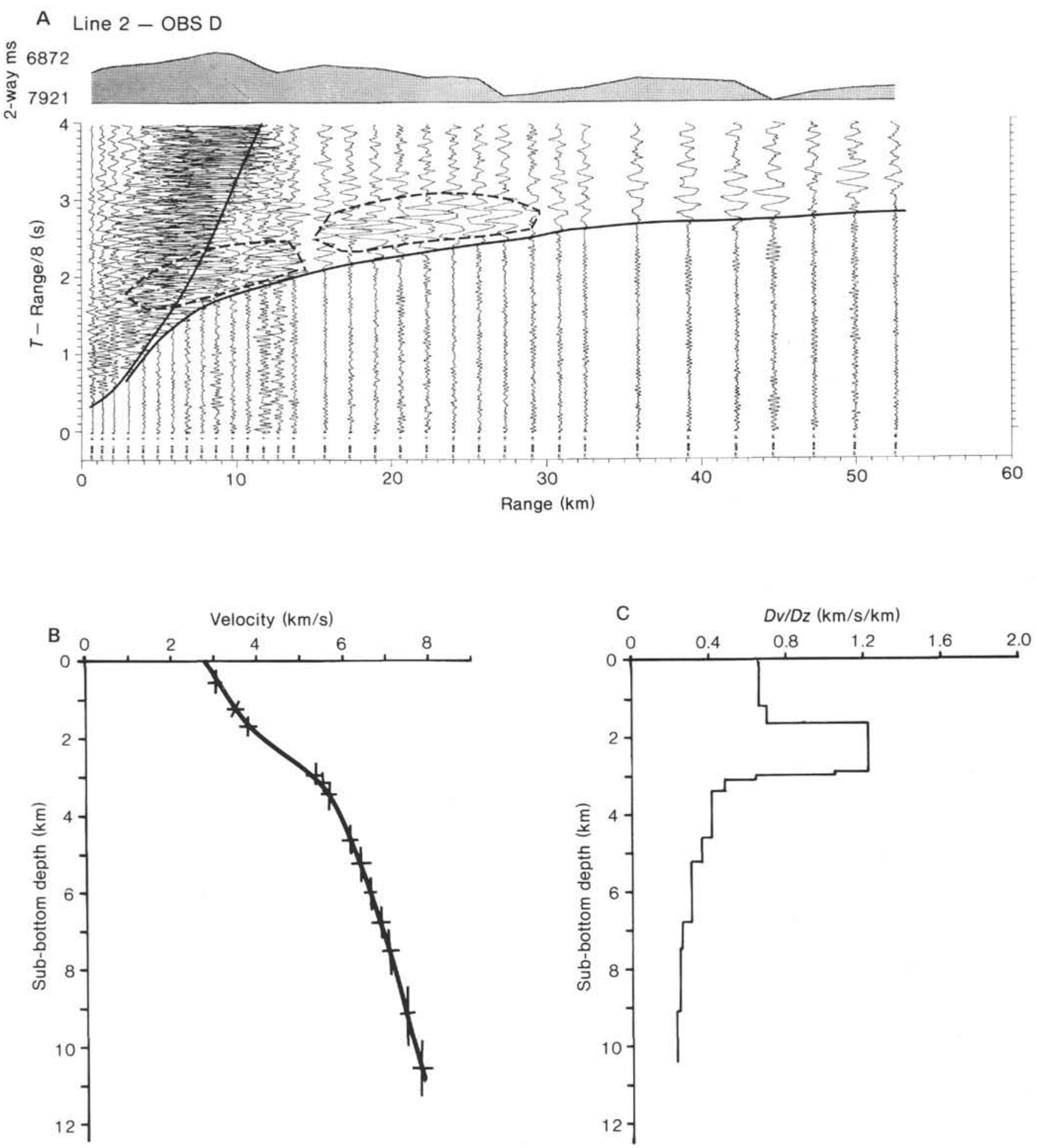

Figure 4. A. Expanded view of first arrivals shown in Figure 3. Circled portions are prominent second arrivals not matched by the traveltime curve (solid line) generated by the velocity-depth function shown in Figure 4B. The water-wave arrival is also indicated by solid line of high slope between 0 and $10 \mathrm{~km}$ range. B. Velocity-depth function derived for line 2 from inversion of first-arrival traveltimes using the Dorman and Jacobson (1981) method. Error bars are marked at each observation used in constructing the solution. C. Change of velocity gradient with depth, the derivative of the function shown in Figure 4B. This figure illustrates more dramatically the rapid increase of velocity with depth in the $1.5-3 \mathrm{~km}$ depth interval. 


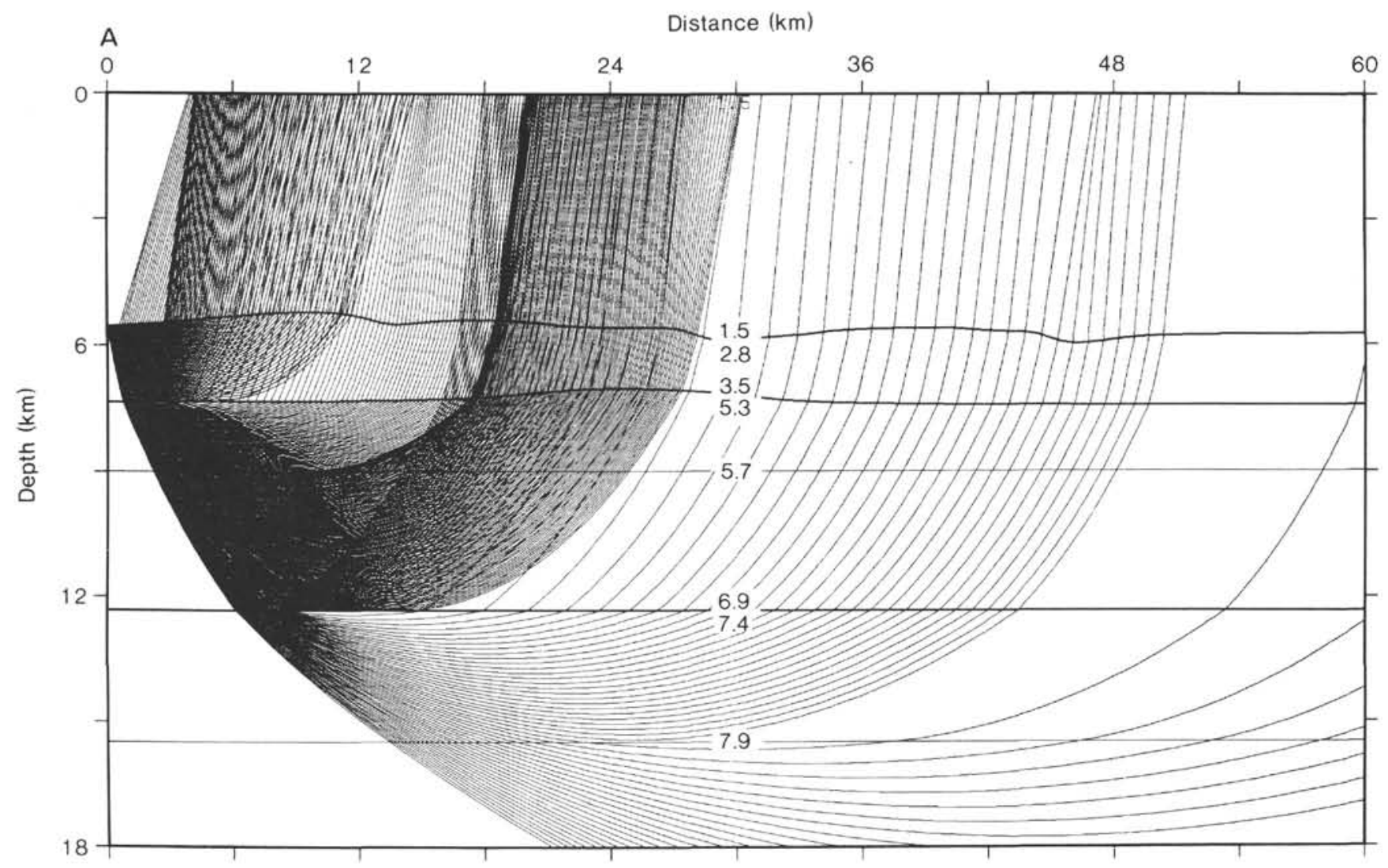

Figure 5. A. Sample raytrace through the preferred model of the velocity structure under line 2. For this and subsequent raytrace illustrations, the following are true: (1) numbers centered within the raytrace diagram are velocities in $\mathrm{km} / \mathrm{s}$; (2) dark lines mark velocity discontinuities; and (3) light lines mark changes in velocity gradient. (N.B.: details of the lower crust-upper mantle transition will vary slightly among the raytraces displayed for the various shot lines. These differences reflect the fact that details of this transition are not adequately resolved by our data set.) B. Line 2 data compared with the synthetic generated from the model shown in Figure 5A. Both the real and the synthetic data are shown with traveltime curves (generated from arrival times of the rays traced in Fig. 5A) superimposed.

features of the data. The main difference between the two models is that the refined model shows the existence of first-order discontinuities at $1.8-2.0 \mathrm{~km}$ sub-bottom depth, an abrupt increase from 3.5 to $5.3 \mathrm{~km} / \mathrm{s}$, and, at $7 \mathrm{~km}$ sub-bottom depth, a change from 6.95 to $7.45 \mathrm{~km} / \mathrm{s}$ (Fig. 6). The first discontinuity had already been implied in the traveltime inversion; the deeper discontinuity is required by the presence of a triplication in the traveltime curve for the range from 17 to $28 \mathrm{~km}$.

The presence of the prominent discontinuity at a depth of 1.8-2.0 km immediately suggests to us some geophysical implications. If our velocity-depth function is superimposed on a reasonable tectonic model (Fig. 7), the first-order discontinuity identified in our seismic refraction data appears roughly to coincide with the strong reflector evident in the multichannel data. Both these data sets imply an abrupt change of materials at the plate boundary. Velocities above the interface are in the range of $2.9-3.5 \mathrm{~km} / \mathrm{s}$. Whereas these velocities are higher than some measured for chalks, oozes, and mudstones from the lower slope (1.5-1.8 km/s range), they are lower than measurements made on altered igneous rocks and limestones $(3-4 \mathrm{~km} / \mathrm{s})$ cored from the same locale (Aubouin, von Huene, et al., 1982). The velocities indicated may thus represent an average for the rocks present in the lower slope.
One question we tried to address in our analysis is whether detail of the plate-interface zone can be observed in the seismic refraction data. The top of the subducting Cocos Plate is covered with approximately $400 \mathrm{~m}$ of sediments with a high fluid content. The trench axis is filled in places with several hundred meters of soupy turbidite material (Moore et al., 1982). It might be assumed that when these materials were subducted, they would comprise a 400 - to 500 -m thick section of low-velocity material. Therefore, we should see evidence for a small velocity inversion, corresponding to these sediments, between overlying Caribbean Plate limestones and serpentinized igneous rocks, and the underlying Cocos Plate ocean crust. Indeed, multichannel seismic data (R. von Huene, pers. comm., 1983) show several tenths of a second of flat-lying reflectors sandwiched between the incoherent reflections of the lower slope and the irregular but highamplitude reflector interpreted as Cocos Plate ocean crust. To test whether we could observe a corresponding velocity inversion in our seismic refraction data, we generated a model that included a $400-\mathrm{m}$ thick section of $1.7 \mathrm{~km} / \mathrm{s}$ velocity between the $3.5-\mathrm{km} / \mathrm{s}$ and $5.3-\mathrm{km} / \mathrm{s}$ sections, and then calculated the corresponding raytraces. We tried various permutations on this basic model, both to ascertain whether any models could be categorically discarded and to see whether our original model could be im- 


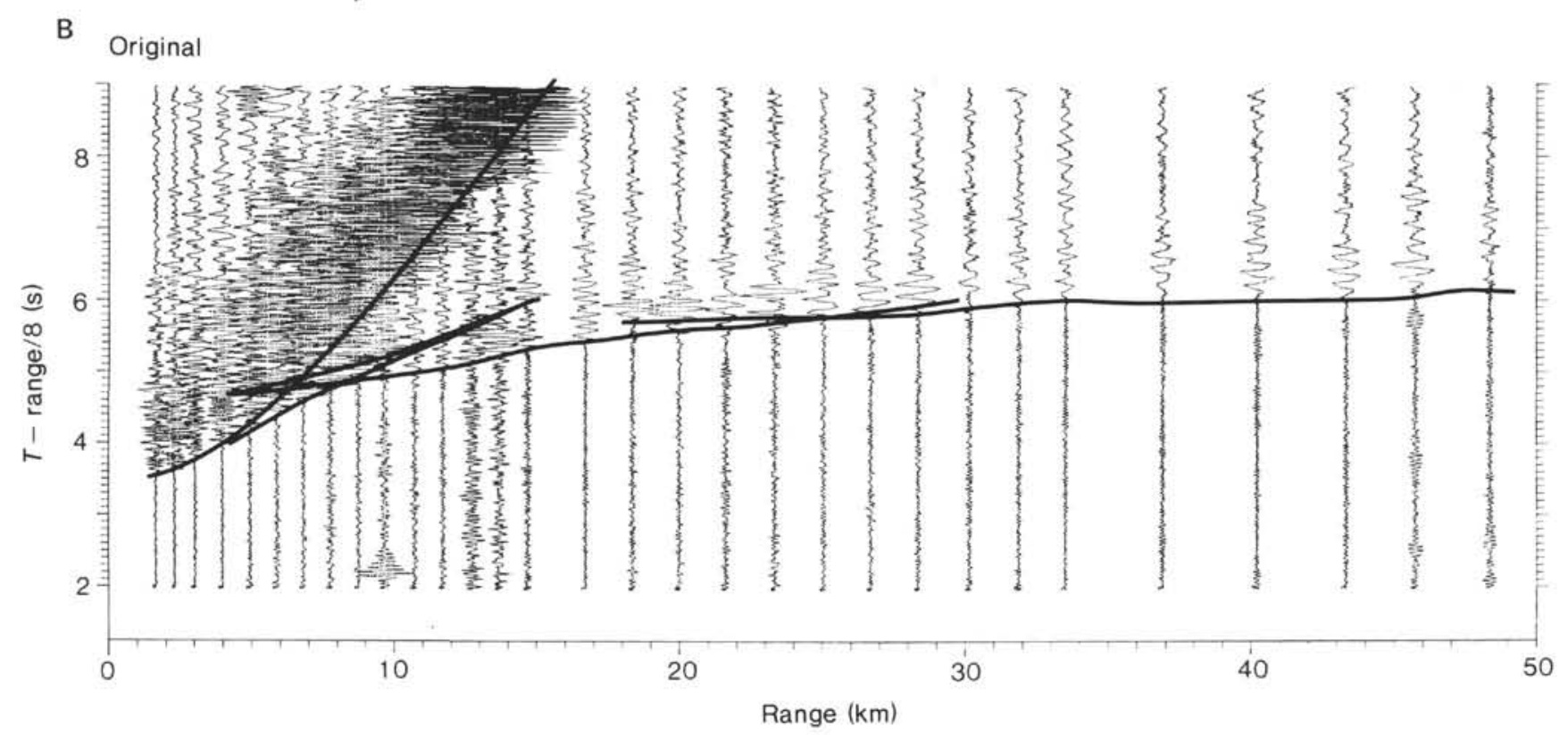

Bathymetry
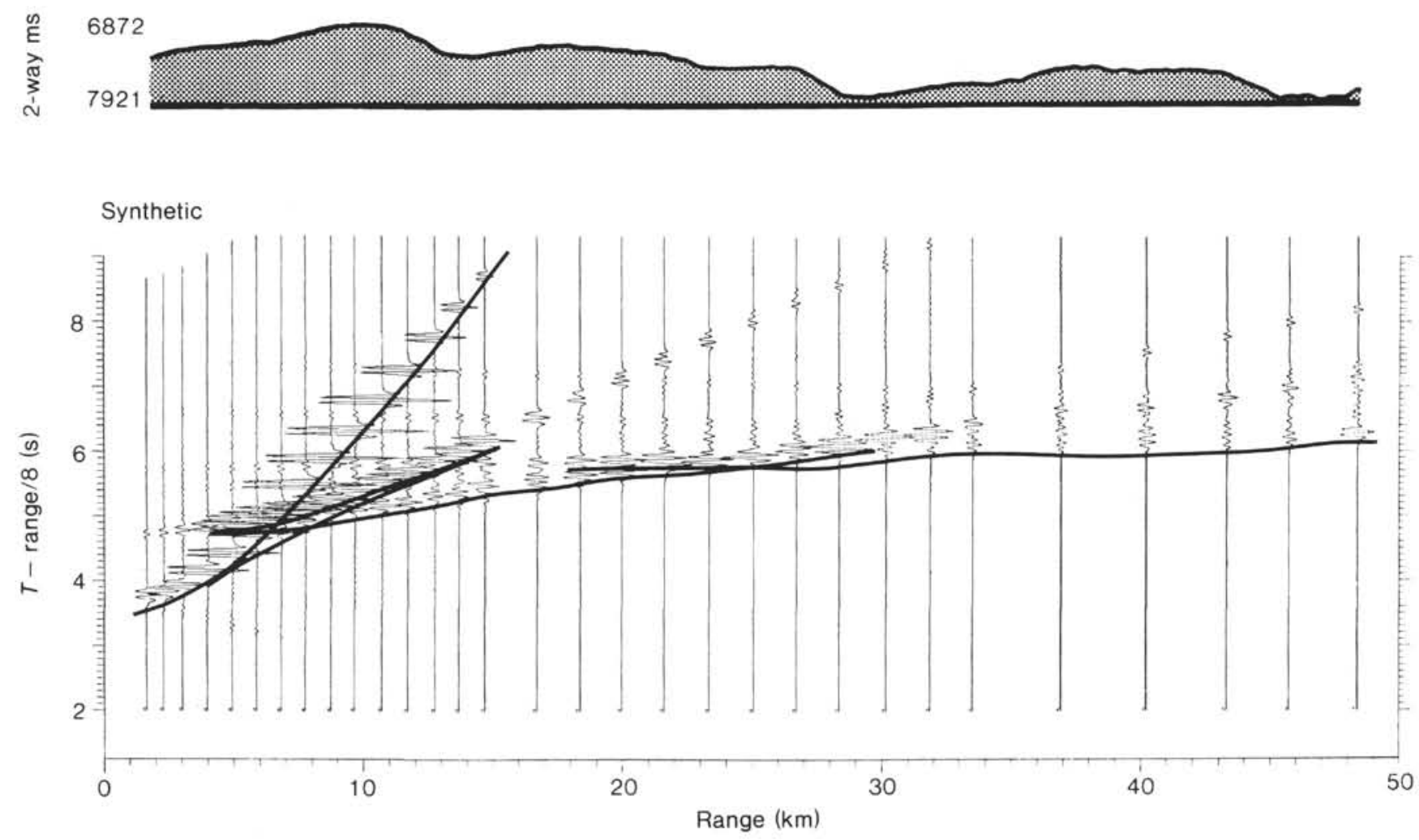

Figure 5. (Continued).

proved. The result of both the preceding lines of investigation was negative: we could not categorically prove the existence of such a velocity-inversion zone from our data. We can conclude that (1) the seismic refraction data do not have the resolution to discriminate such a feature as $400 \mathrm{~m}$ of sediment, (2) the sediment is not continuous in thickness and/or velocity, or (3) any subduct- ed sediments present may already be partially dewatered and compacted (Burst, 1976), and are now at a higher velocity than $1.7 \mathrm{~km} / \mathrm{s}$. In any event, we think that it would be difficult to use seismic refraction data as a tool to determine the existence of layer $400 \mathrm{~m}$ or less in thickness. Much of the frequency content of the seismic data is in the $5-12 \mathrm{~Hz}$ band, implying wavelengths of $0.4-0.8$ 


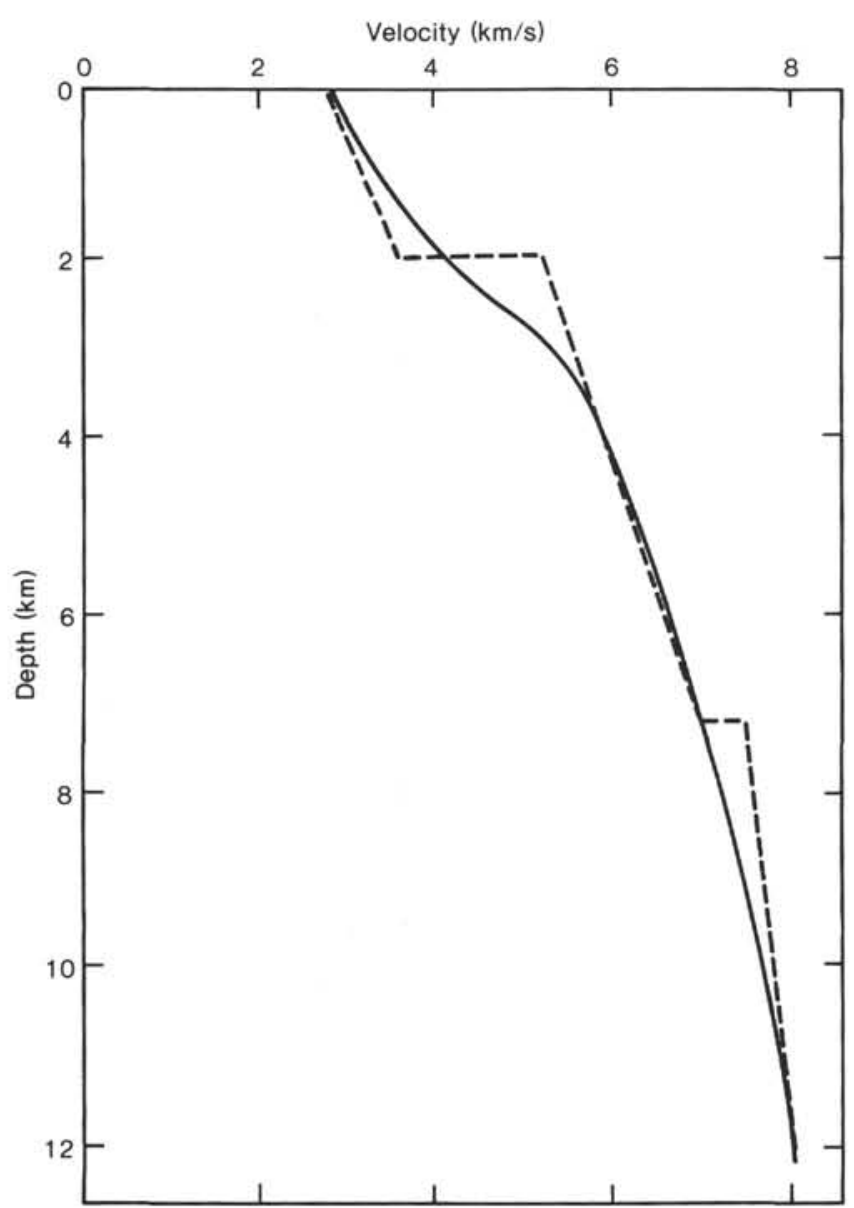

Figure 6. Velocity-depth functions derived for line 2. The solid line is the function derived through inversion of first-arrival traveltime data by using the Dorman and Jacobson (1981) method. Dashed line gives the preferred model, derived through raytracing and synthetic composition and comparison with the data.

$\mathrm{km}$ and corresponding resolving potential of $200-400 \mathrm{~m}$ in the best case.

\section{Line 4}

We suspected that the velocity structure for the line 4 data (Figs. 8 and 9) would be similar to that determined for line 2 . We also chose, however, to interpret line 4 independently, so as not to bias our results. The analysis process followed was identical to that for line 2. Inversion of first-arrival traveltimes (for the northwestern side of line 4 only) provided us with an initial velocity-depth structure. Subsequent iterative raytracing through this model (with bottom topography included) brought us to a closer match to observed first and second arrivals.

We believe that there are two important results of the raytrace analysis (Fig. 10A). First, a distinction between the shallow structure of line 2 and line 4 can be perceived. The line 4 data seem to require higher velocities in the upper-plate section than line 2 , the line closest to the trench. As a further test of this result, we interchanged the line 2 and line 4 models, generated traveltime curves for them, and compared these with the data (Fig. 11), demonstrating conclusively that the structures are not

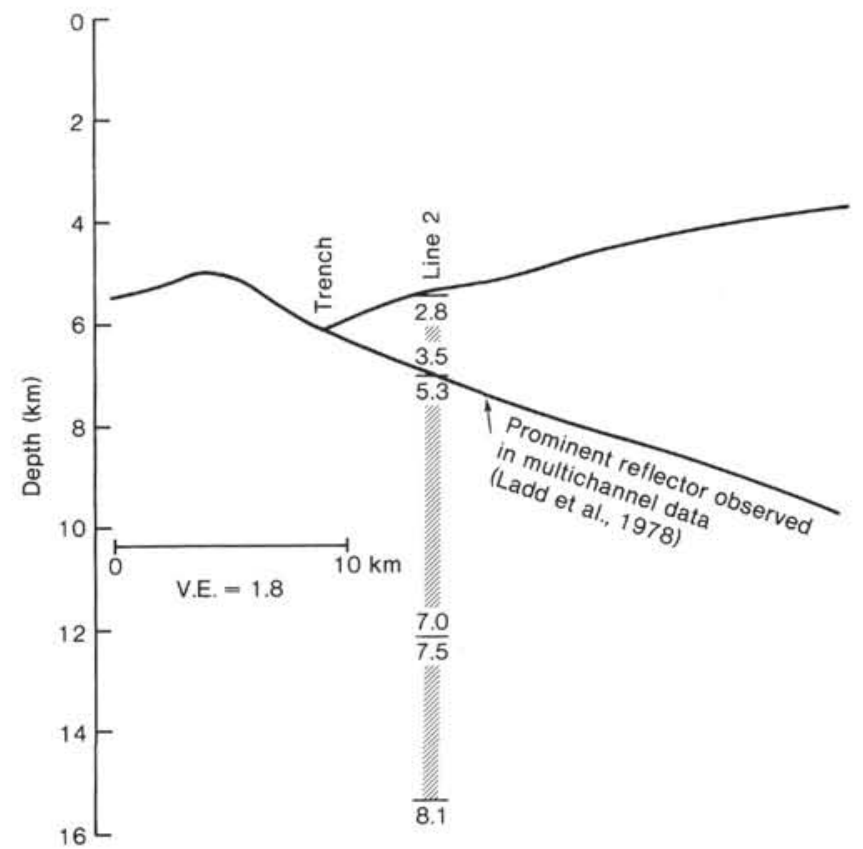

Figure 7. Superposition of the preferred velocity-depth function developed for line 2 onto a diagrammatic cross-section perpendicular to trench-axis strike. The plate interface is here defined as a prominent reflector observed in multichannel seismic data (Ladd et al., 1978; Ladd et al., 1982).

interchangeable. Therefore, we have observed a landward increase in velocity in the materials of the overlying plate, between lines shot $3 \mathrm{~km}$ apart over the lower slope.

The second finding is the apparent thinning of the "upper-plate" material toward the trench crossing (Fig. 10A). This result is not unexpected, of course, but we point it out because it appears to be consistent with our previous assumptions. The thinning was required to match the traveltime data. Although forward modeling rarely attains a unique explanation of the data, the model we obtained represents the simplest solution possible.

\section{Lines 3 and 5}

In our analysis of lines 3 and 5 (Figs. 12 and 13), we utilized as a basic constraint on our interpretations that velocity-depth function agreement must occur at the crossover of the lines with lines 2 and 4 . Also, we expected lines 3 and 5 to show similar features, as line 3 is merely shorter than line 5 and oriented at a different angle to the trench axis.

The cross-line data are modeled simply, with a Cocos Plate dipping approximately $8^{\circ}$ landward, which also corresponds to the dip of the reflector observed in the multichannel data (Fig. 14A). The reflection off the plate/ plate boundary is particularly evident on the left-hand side of the split-spread, in the $0-20-\mathrm{km}$ range (Fig. 14B). Velocities in the overlying (Caribbean) plate appear to increase landward. Thirty to forty kilometers from the trench axis, velocities in the subduction complex reach $5.2-5.5 \mathrm{~km} / \mathrm{s}$ at the Cocos/Caribbean plate boundary. This means that the velocity contrast, once so evident near the trench, would no longer be evident at distances $30-40 \mathrm{~km}$ from the trench. This decrease in velocity con- 
A

Line 4 - OBS D
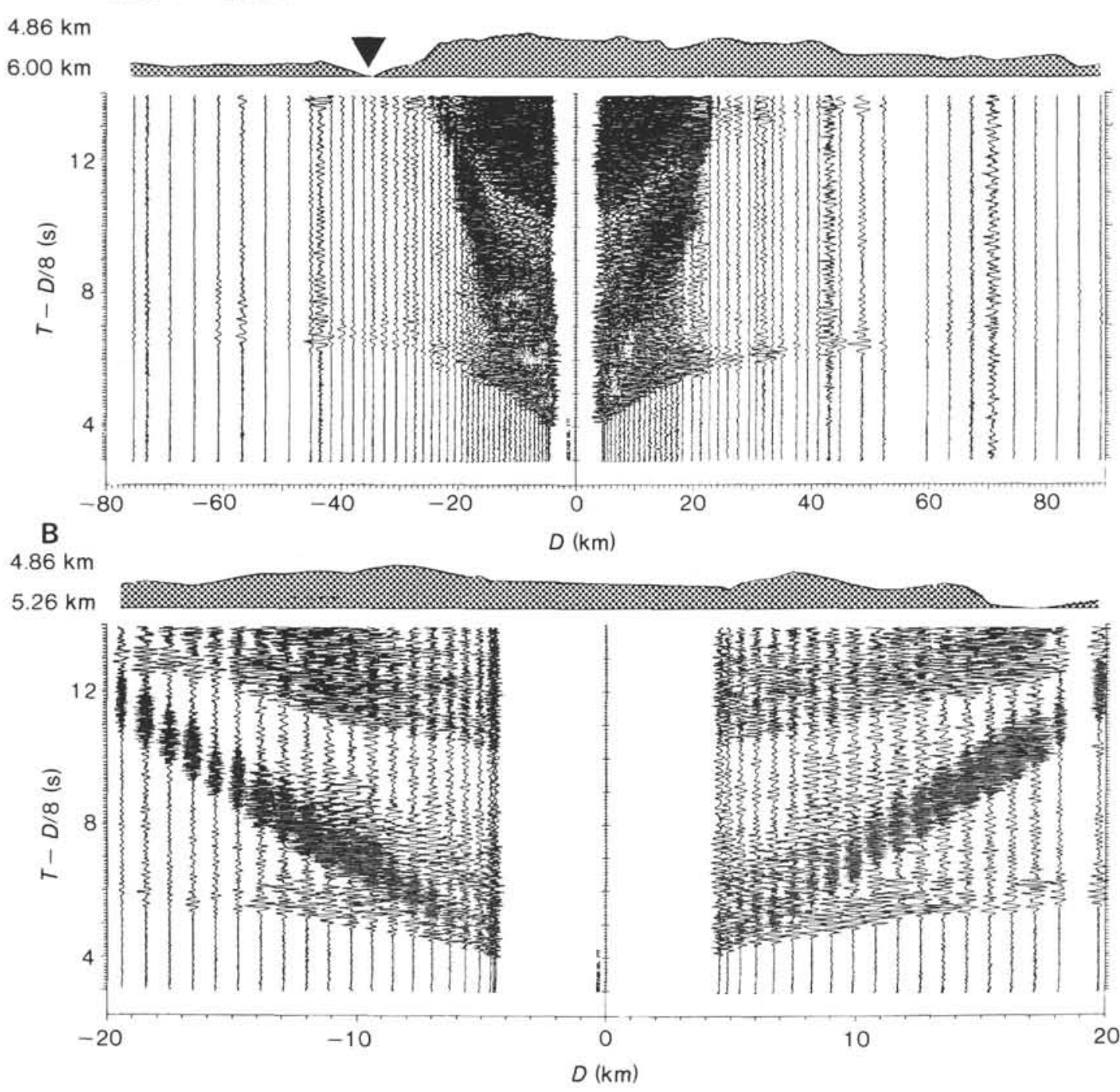

Figure 8. A. Record section for line 4, recorded by OBS D. Same comments as for Figure 3A. Arrow indicates trenchaxis crossing. Northwest is to the right. B. Detail of record section shown in Figure 8A, \pm 20 -km range.

trast is significant in the light of the observation, made by Ladd et al. (1982), that the prominent reflector they observe near the trench, at depths corresponding to the plate interface, disappears $30 \mathrm{~km}$ from the trench axis. If there were no longer a strong impedance contrast between overriding and underriding plates, there would be no reflecting interface.

As part of our investigation of the data for lines 3 and 5, we searched for classes of models that were clearly incompatible with our data, so as to narrow the field of possibilities. We particularly wanted to ascertain whether the trend indicated by the comparison of the data for lines 2 and 4 -that of landward velocity increase in the overriding plate-was confirmed through analysis of the cross-line data. Given as known the bathymetry under the shotline, and the $8^{\circ}$ dip of the plate boundary defined by the multichannel seismic data, we constructed a model of the overriding wedge using the velocitydepth function determined for the line 2 data. The resulting comparison indicated that velocities must indeed increase in the upper plate. Otherwise, the mismatch between real and synthetic traveltime data is greater than a second.

The other aspect of the overriding-wedge velocity structure that we tried to constrain was the rate of velocity increase landward-that is, does the velocity increase abruptly or gradually landward of the trench? We also wanted to determine whether or not we could observe any traveltime-curve perturbations caused by possible highvelocity slabs of ocean crust imbedded in the upperplate material. We found that reasonable models that included slabs of dimensions greater than $1 \times 5 \mathrm{~km}$ could not be constructed and still match the traveltime data collected over the lower slope. The only portions of the line 3 data which evidence the negative delay times expected for travel paths through high-velocity blocks of material are the last two shots on the left-hand side of the line (Fig. 14B). We are hesitant to base an interpretation on two data points. Therefore, we conclude that our data do not provide strong evidence of the existence 
A Line 4 - OBS $J$
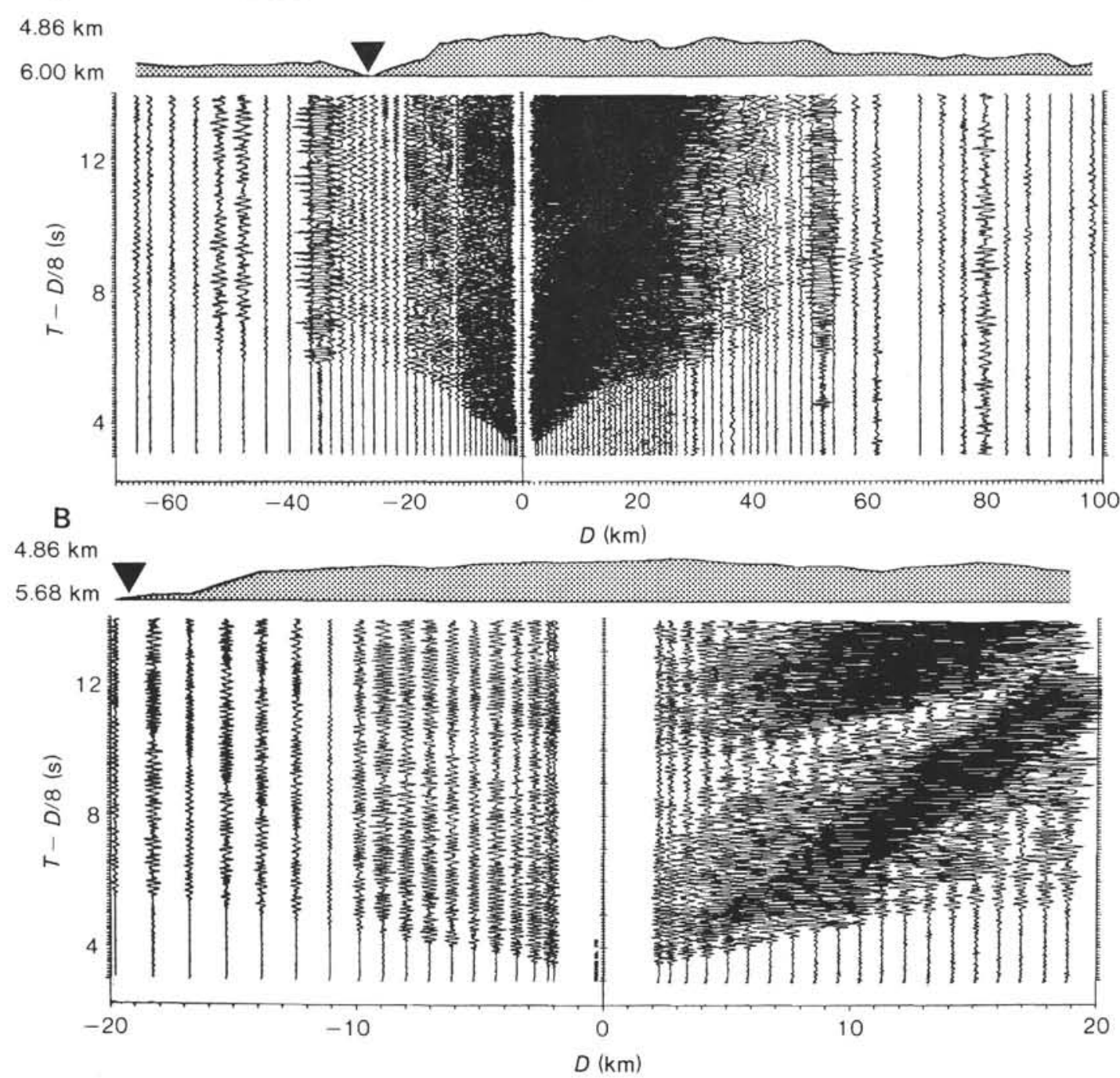

Figure 9. A. Record section for line 4, recorded by OBS J. Same comments as for Figure 3A. B. Detail of record section shown in Figure 9A, \pm 20 -km range.

of such slabs imbedded in the lower slope. Instead, the velocity seems to increase gradually in the overriding wedge. We obtained a slightly better match to the data if we modeled a fairly rapid rate of increase in the overriding wedge within the first 5-10 $\mathrm{km}$ from trench, and then a more gradual increase (Fig. 15).

\section{DISCUSSION}

Comparison of the three seismic refraction studies conducted in the lower-slope region (our study; Ibrahim et al., 1979; Shor and Fisher, 1961) with an accepted model for ocean crust (Spudich and Orcutt, 1980) illustrates the overall difference between the two tectonic provinces (Fig. 16). The distinction is in the greater thickness of lowervelocity material $(3-5 \mathrm{~km} / \mathrm{s})$ in the lower slope, which no doubt corresponds to the subduction-complex rocks.

Dissimilarities do exist between the three lower-slope profiles. We do not dismiss these differences, but suggest that they may result from differing data quality and methods of interpretation, rather than from radically different geology. The overall picture of the lower slope, which is shared by the three investigations, is that velocities increase landward of the trench in the overriding wedge. The analysis of Ibrahim et al. (1979) showed that this increase in velocity may be discontinuous, caused by high-velocity sections imbedded in surrounding material of lower velocity. They interpreted these sections as pieces of Cocos Plate ocean crust, slivered off the subducting plate and incorporated into the subduction complex. These accreted slabs, which might have dimensions of $10 \mathrm{~km}^{2}$, would possibly appear similar to rocks of the Santa Elena Peninsula if drilled.

The results of our data analysis do not appear consistent with existence of high-velocity slabs $(5.3-5.6 \mathrm{~km} / \mathrm{s}$, in a matrix of $3-4 \mathrm{~km} / \mathrm{s}$ material), at least within 30 to $40 \mathrm{~km}$ of the trench. In fact, our data seem to imply gradually increasing velocities of materials away from the trench. Still, we cannot discount the possible existence 


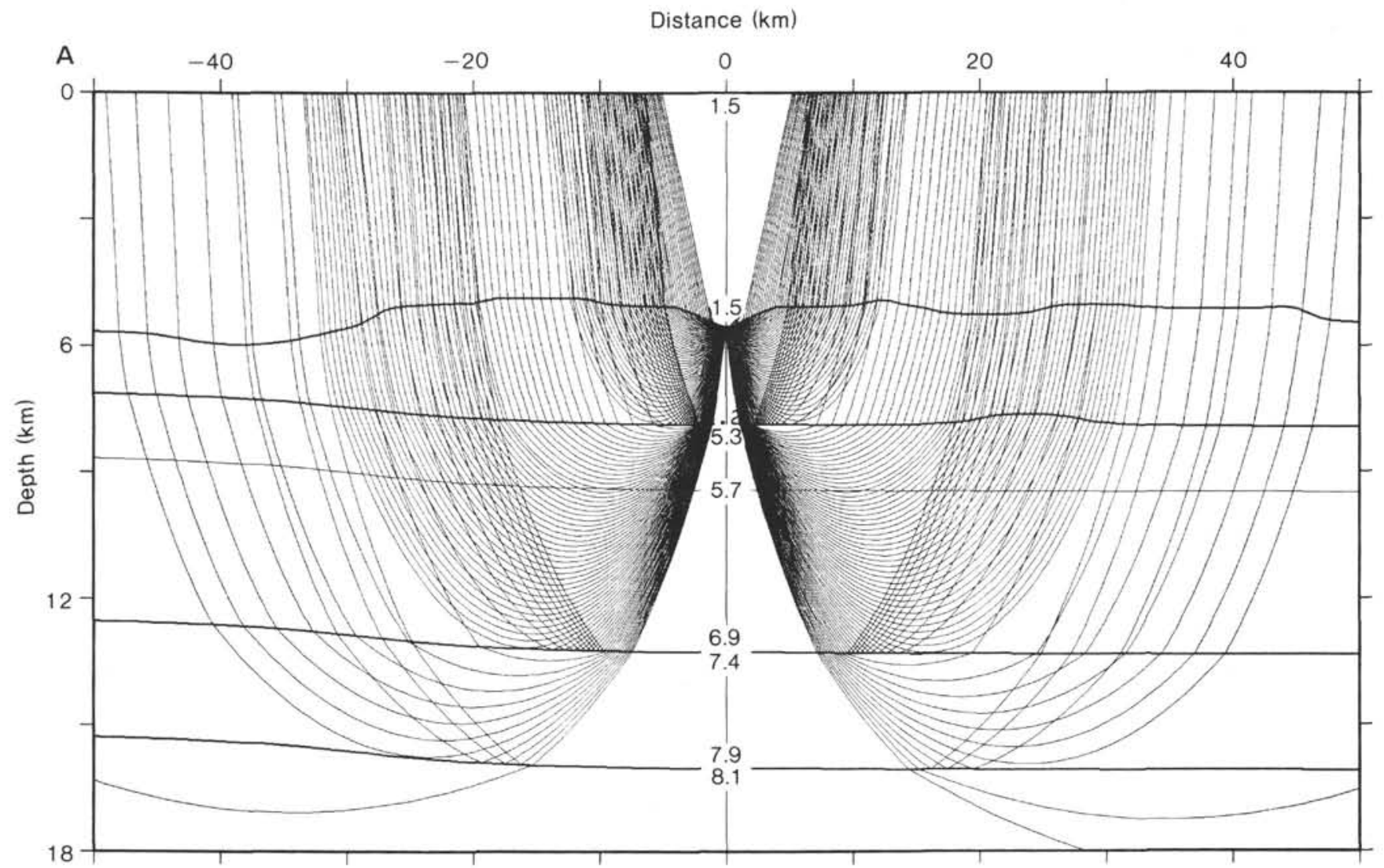

B

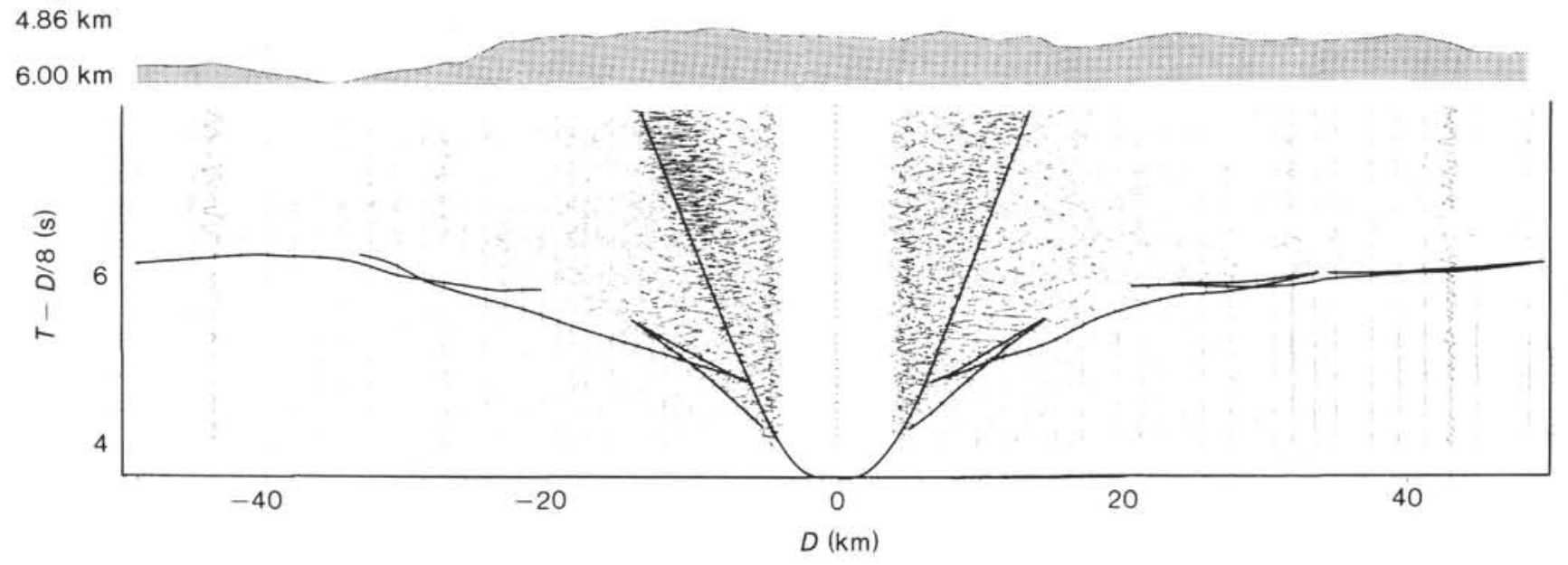

Figure 10. A. Line 4, OBS D model with raytrace superimposed. Same comments as for Figure 5A. B. Traveltime curves generated with the model shown in Figure 10A, superimposed on the line 4, OBS D data.

of high-velocity sections landward of our survey. For example, the multichannel seismic reflection data presented by Ladd et al. (1982) demonstrate the existence of landward-dipping slabs $45 \mathrm{~km}$ from the trench axis.

Our preferred model for the lower slope includes a gradual landward increase in velocity in the overriding plate (Fig. 15). This increase would be consistent with drilling evidence of increasing deformation trenchward. In general, the tensional and/or compressional forces operating during the subduction process seem primarily to affect a small section of the subduction complex adjacent to the trench. This strained portion is faulted and fractured; and it is intruded by fluids escaping from the subducting plate. The pervasive fracturing of the subduction-complex rocks would lead to a substantial decrease in the velocities observed. Landward of this im- 
Line 2 - OBS D

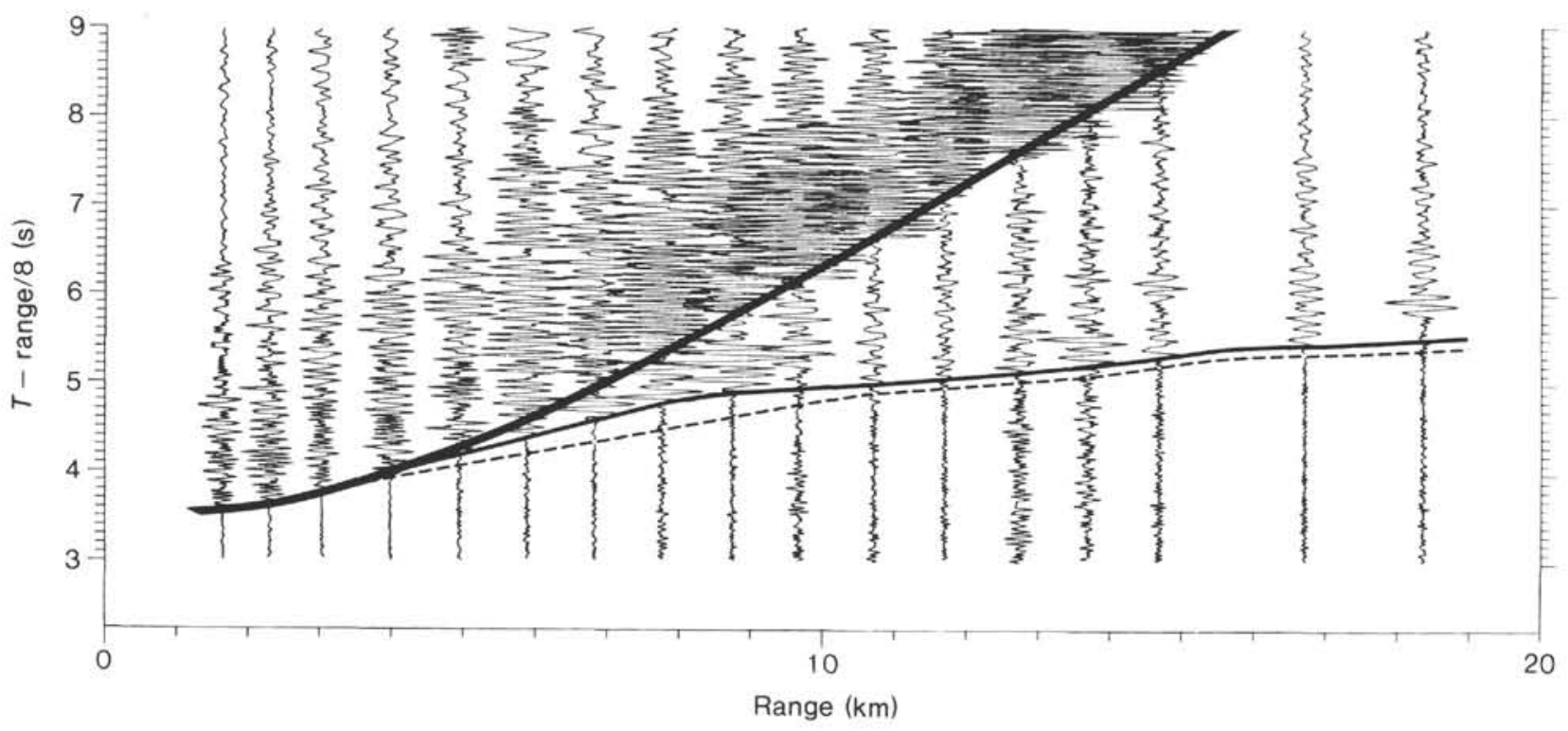

Line 4 - OBS $J$

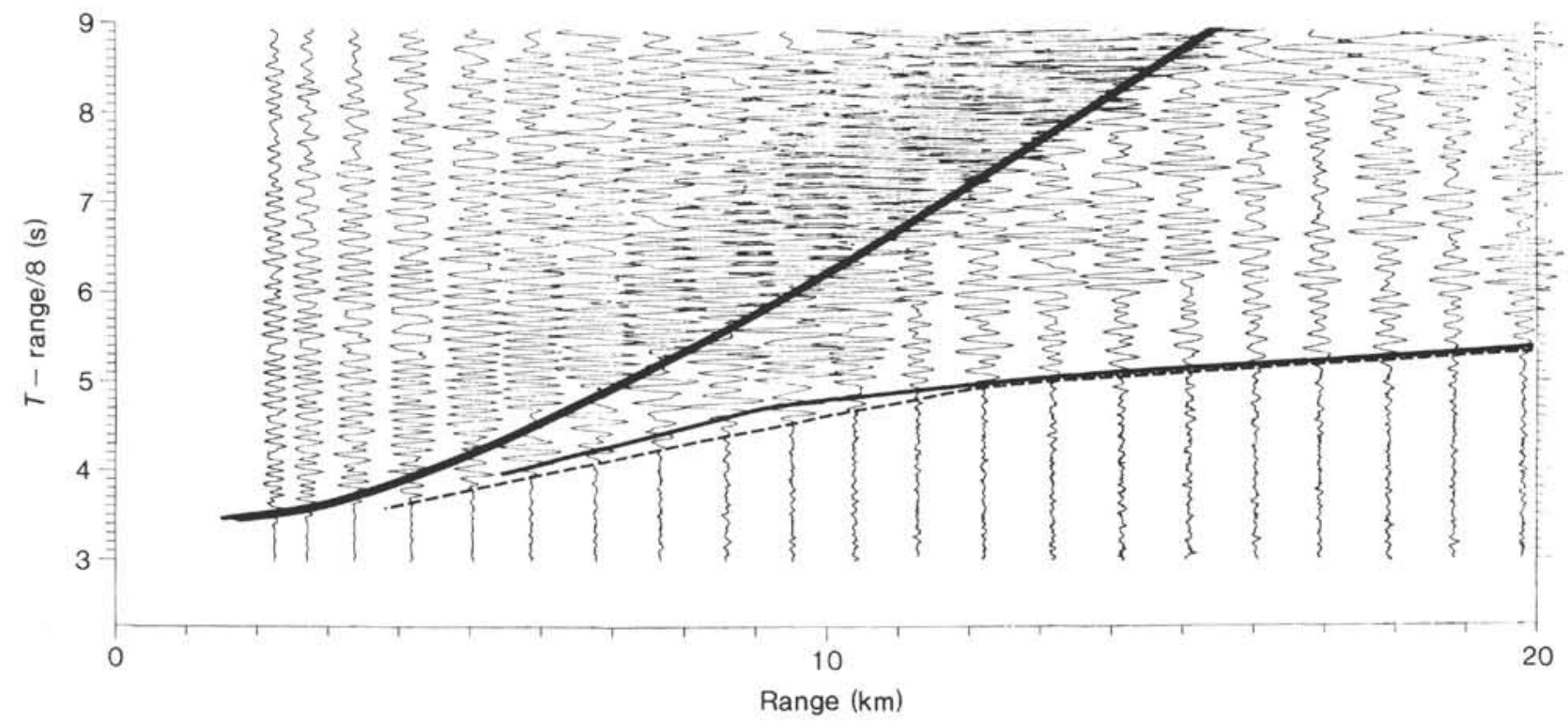

Figure 11. Comparison of fit of models for lines 4 and 2. Traveltime curves have been generated for both models and superimposed on both lines. The heavy solid line shows the water-wave arrivals. The thin solid line in both cases shows the traveltime curve generated by using the function derived for line 2; the dashed line shows traveltime curves calculated from the line 4 model. The mismatching indicates that the models are not interchangeable, and that the velocity structure of the lower-slope materials changes with increasing distance from the trench axis.

mediate subduction-related tectonism, velocities might gradually increase to those characteristic of the intrinsic velocities of the materials present.

\section{ACKNOWLEDGMENTS}

We thank J. Carter, who helped collect the data and who contributed substantially to the initial data reduction. T. Schreiner and J. B. Sinton provided traveltime-inversion and raytracing programs, respectively, and helpful advice on how to use them. Discussions with R. von Huene were helpful in focusing the paper. The paper was improved through reviews by G. Moore, P. Fryer, N. Frazer, and an anonymous reviewer. Editorial assistance was provided by $\mathrm{R}$. Pujalet. We thank the personnel of the Kana Keoki and the Leg 67 crew and staff of the Glomar Challenger. This research was supported by the Office of Naval Research, and by the OMD Region II Synthesis Project, University of Texas subcontract UT-25-81-2.

\section{REFERENCES}

Aubouin, J., Stephan, J. -F., Renard, V., Roump, J., and Lonsdale, P., 1982. A Seabeam survey of the Leg 67 area (Middle America Trench off Guatemala). In Aubouin, J., von Huene, R., et al., Init. Repts. DSDP, 67: Washington (U.S. Govt. Printing Office), 733-738. 
Aubouin, J., von Huene, R. E., Azéma, J., Blackinton, G., Carter, J. A., Coulbourn, W. T., Cowan, D. S., Curiale, J. A., Dengo, C. A., Faas, R. W., Harrison, W., Hesse, R., Hussong, D. M., Ladd, J. W., Muzylov, N., Shiki, T., Thompson, P. R., and Westberg, J., 1982. Site 494: Middle America Trench lower slope. In Aubouin, J., von Huene, R., et al., Init. Repts. DSDP, 67: Washington (U.S. Govt. Printing Office), 27-78.

Burst, J. F., 1976. Argillaceous sediment dewatering. Ann. Rev. Earth Planet. Sci., 4:293-318.

Couch, R., Woodcock, S., 1981. Gravity and structure of the continental margins of southwestern Mexico and northwestern Guatemala. J. Geophys. Res., 86:1829-1840.

Dickinson, W. R., and Seely, D. R., 1979. Structure and stratigraphy of forearc regions. Am. Assoc. Pet. Geol. Bull., 63:2-31.

Dorman, L. M., and Jacobson, R. 1981. Linear inversion of body wave travel time data. Geophysics, 46:138-151.

Frazer. L. N., and Phinney, R. A., 1980. The theory of finite frequency body wave synthetic seismograms in inhomogeneous elastic media. Geophys. J. R. Astron. Soc., 63:691-717.

Gebrande, H., 1976. A seimic ray tracing method for two-dimensional inhomogeneous media. In Giese, P., Prodehl, C., and Stein, A. (Eds.), Explosion Seismology in Central Europe: Data and Results: New York (Springer-Verlag), pp. 162-167.

Ibrahim, A. -B. K., Latham, G. V., and Ladd, J., 1979. Seismic refraction and reflection measurements in the Middle America Trench offshore Guatemala. J. Geophys. Res., 84:5643-5649.

Kempner, W. C., and Gettrust, J. F., 1982. Ophiolites, synthetic seismograms, and ocean crustal structure 1. Comparison of ocean bottom seismometer data and synthetic seismograms for the Bay of Islands ophiolite. J. Geophys. Res., 87:8447-8462.

Ladd, J. W., Ibrahim, A. -B. K., McMillen, K. J., Latham, G. V., von Huene, R. E., Watkins, J. S., Moore, J. C., and Worzel, J. L. 1978. Tectonics of the Middle America Trench offshore Guatemala. Int. Symp. February 4, 1976 Gutemala Earthquake and the Reconstruction Process.

Ladd, J. W., Ibrahim, A. -B. K., McMillen, K. J., Latham, G. V., and von Huene, R. E., 1982. Interpretation of seismic reflection data of the Middle America Trench offshore Guatemala, In Aubouin, J., von Huene, R., et al., Init. Repts. DSDP, 67: Washington (U.S. Govt. Printing Office), 675-689.

Moore, G. F., Lonsdale, P., and von Huene, R. E., 1982. Near-bottom observations of the Middle America Trench off Guatemala. In Aubouin, J., von Huene, R., et al., Init. Repts. DSDP, 67: Washington (U.S. Govt. Printing Office), 707-718.

Purdy, G. M., 1982. The correction for the travel time effects of seafloor topography in the interpretation of marine seismic data. $J$. Geophys. Res., 87:8389-8396.

Seely, D. R., Vail, P. R., and Walton, G. G., 1974. Trench slope model. In Burke, G. A., and Drake, C. L., (Eds.), The Geology of Continental Margins: New York (Springer) pp. 249-260.

Shor, G. G., and Fisher, R. L., 1961. Middle America Trench: Seismic refraction studies. Geol. Soc. Am. Bull., 72:721-730.

Sinton, J. B., 1982. Detailed geophysical studies of two-dimensional structures at active plate margins using seismic refraction and earthquake data [Ph. D. dissertation]. University of Hawaii at Manoa.

Sinton, J. B., and Frazer, L. N., 1982. A method for the computation of finite frequency body wave synthetic seismograms in laterally varying media. Geophys. J. R. Astron. Soc., 71:37-55.

Spudich, P., and Orcutt, J., 1980. Petrology and porosity of the oceanic crust: results from waveform modeling of seismic refraction data. J. Geophys. Res., 85:1409-1433.

Sutton, G. H., Kasahara, J., Ichinose, W. N., and Byrne, D. A., 1977. Ocean bottom seismograph development at the Hawaii Institute of Geophysics. Mar. Geophys. Res., 3:153-177.

von Huene, R., and Aubouin, J., 1982. Summary-Leg 67: Middle America Trench transect off Guatemala. In Aubouin, J., von Huene, R., et al., Init. Repts. DSDP, 67: Washington (U.S. Govt. Printing Office), 775-793.

von Huene, R., Ladd, J., and Norton, I., 1982. Geophysical observations of slope deposits, Middle America Trench off Guatemala. In Aubouin, J., von Huene, R., et al., Init. Repts. DSDP, 67: Washington (U.S. Govt. Printing Office), 719-732. 
A Line 3 - OBS D

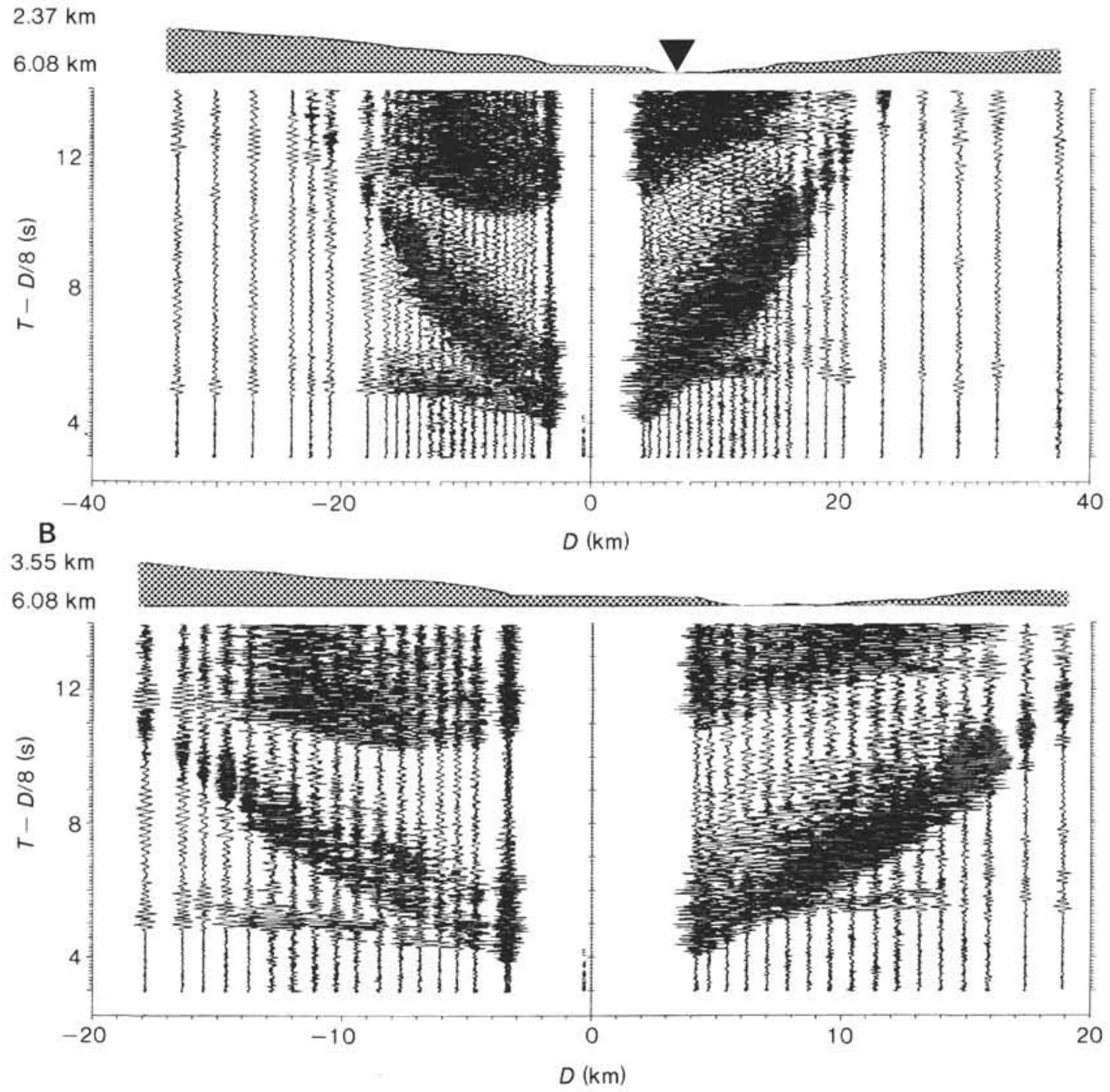

Figure 12. A. Record section for line 3, OBS D. Same comments as for Figure 3A. The arrow indicates the trench-axis crossing. B. Detail of record section shown in Figure 12A, $\pm 20-\mathrm{km}$ range. 
A Line $5-O B S z$
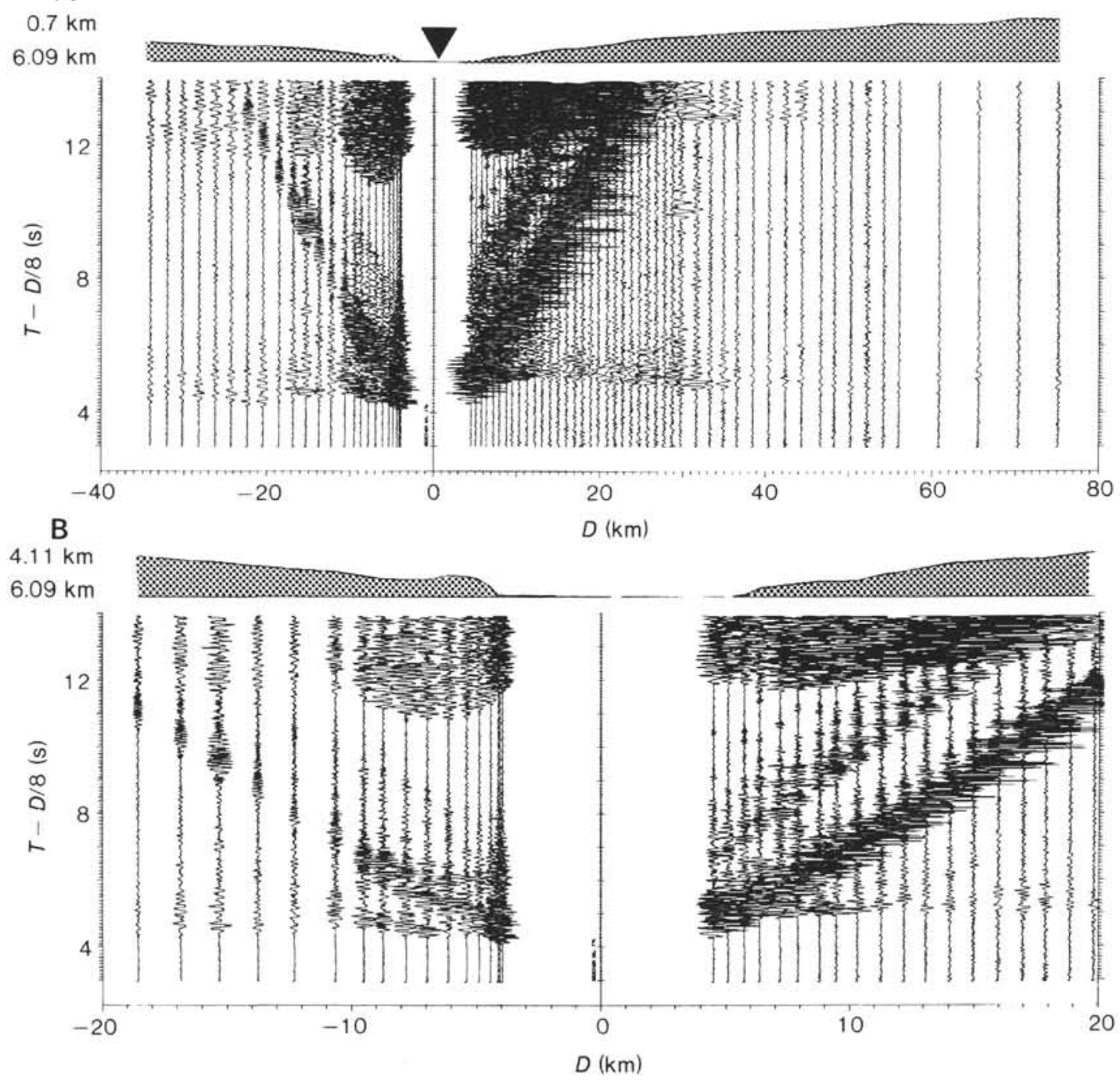

Figure 13. A. Record section for line 5, OBS Z. Same comments as for Figure 3A. The arrow indicates the trench-axis crossing. B. Detail of record section shown in Figure $13 \mathrm{~A},+20-\mathrm{km}$ range. 

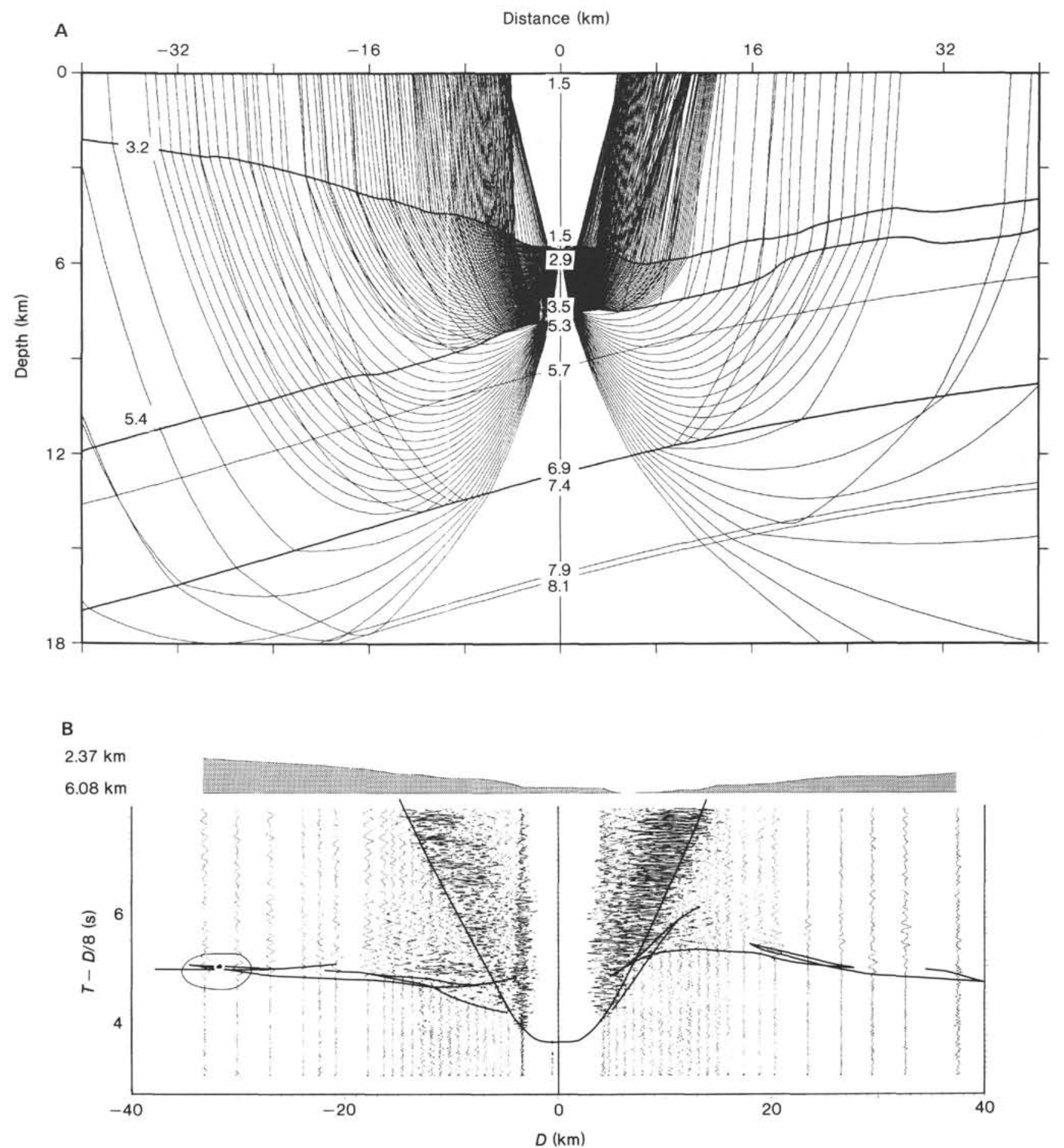

Figure 14. A. Line 3, OBS D model with raytrace superimposed. Only a portion of the line, $\pm 50-\mathrm{km}$ range, is shown for clarity of presentation. A virtually identical model satisfied the line 5 data. B. Traveltime curves generated with the model shown in Figure 14A, superimposed on the line 3 , OBS D data. 


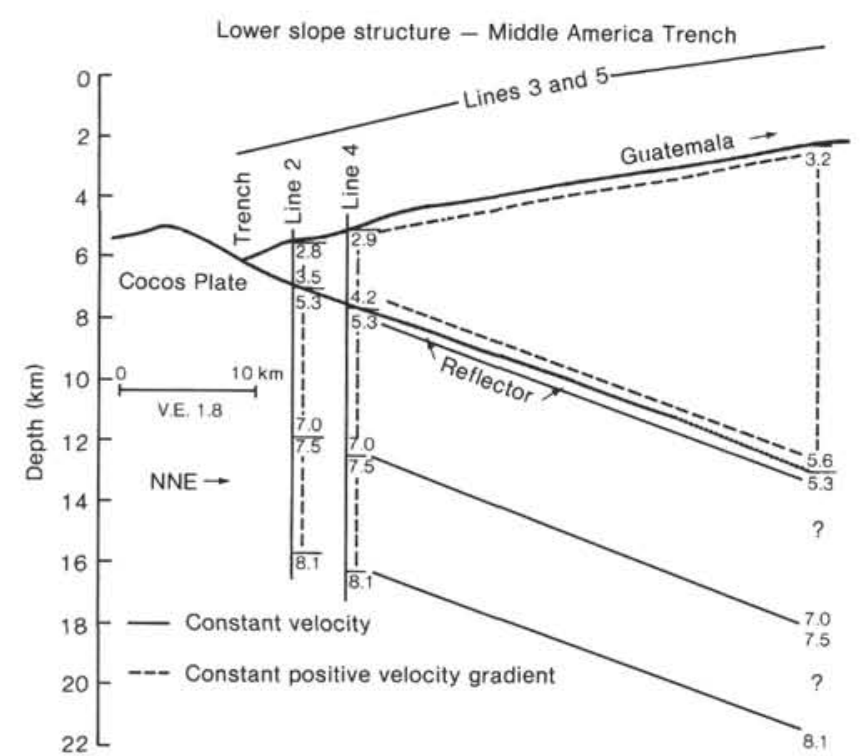

Figure 15. Summary cross section of velocity structure in the Middle America Trench lower slope region. Numbers listed in columns (under headings "Line 2" and "Line 4") are velocities in $\mathrm{km} / \mathrm{s}$.

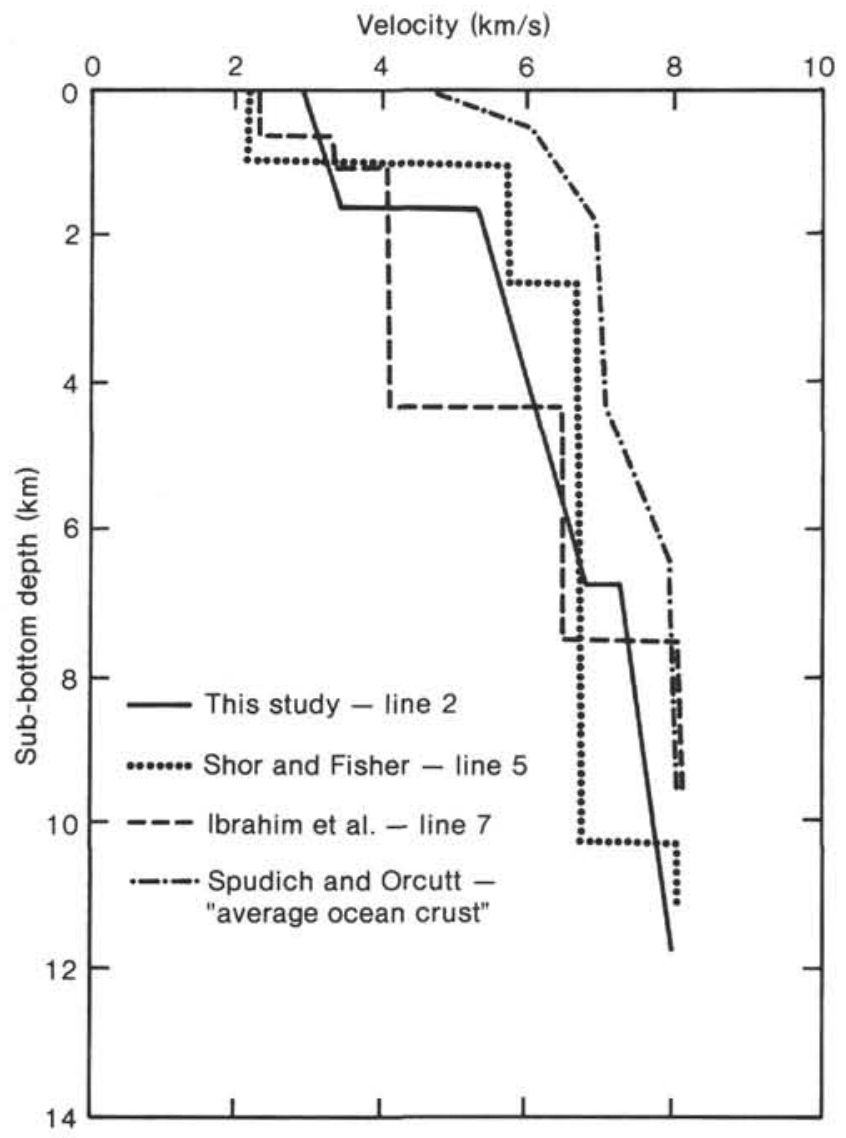

Figure 16. Comparison between MAT-G lower-slope velocity-depth functions (this study; Ibrahim et al., 1979; and Shor and Fisher, 1961) and a standard velocity-depth function derived for ocean crust (Spudich and Orcutt, 1980). 